\title{
Interactions between plots in experiments with the splash-dispersed pathogen Rhynchosporium secalis on winter barley
}

\author{
BY J. F. JENK YN, G. V. DYKE, O. J. STEDMAN AND A. D. TODD \\ AFRC Institute of Arable Crops Research, Rothamsted Experimental Station, Harpenden, Herts AL5 $2 J Q$
}

(Revised MS. received 15 August 1988)

\begin{abstract}
SUMMARY
Experiments of balanced design in harvest years 1981 and 1982 were used to measure interactions between plots of winter barley with different amounts of leaf blotch, caused by the splash-dispersed pathogen Rhynchosporium secalis. On the appropriate transform scales (logarithms of counts and logits of percentages), the effects of extreme treatments on neighbouring plots were up to $30 \%$ of the effects of the same treatments on the plots to which they were applied. Powdery mildew (Erysiphe graminis f.sp. hordei) was commonly least severe in plots with most leaf blotch except soon after fungicide sprays had been applied which, although chosen to decrease leaf blotch, also had short-lived effects on mildew. Consequently, contrasts in mildew between differently treated plots changed sign during the season. The effects of the same treatments on neighbouring plots similarly changed with time but not necessarily in phase with their direct effects. Analyses of the rhynchosporium data that recognized the effects of neighbouring treatments typically had much smaller residual mean squares than analyses that ignored neighbour effects but assumed randomized block designs.

Treatments had mostly small effects on grain yield but these data from two of the experiments showed marked positional variation. Individual plots yields from one of these experiments, testing five treatments, are quoted in the appendix so that they are available to others with an interest in alternative methods, such as nearest-neighbour models, to adjust for local correlations between plots.
\end{abstract}

\section{INTRODUCTION}

Inter-plot interference is a potentially important source of bias in field experiments with any plant pathogen that produces easily dispersed, air-borne spores. Where it occurs the effects of a treatment will often be underestimated and, in spray-timing experiments, it may lead to erroneous conclusions concerning the best time to apply sprays (see, for example, James et al. 1973, 1976; Jenkyn \& Bainbridge, 1974; Bainbridge \& Jenkyn, 1976; Bowen, Teng \& Roelfs, 1984; Parlevliet \& van Ommeren, 1984). Such effects of inter-plot interference on the mean responses to treatments have been called representational errors by van der Plank (1963), because the plots do not truly reflect conditions in the fields they are implicitly assumed to represent. Spore deposition gradients are, however, typically very steep. Predictably, therefore, plots will interact most with their immediate neighbours so that interference will often increase variability in experimental results and hence decrease the precision with which treatment effects are measured.
Such effects of interference have, to a large extent, been ignored but Jenkyn et al. (1979) suggested that, in some experiments, losses in efficiency due to interference might be relatively more important than the effects of interference on the average responses to treatments. This would, for example, often be so in experiments in which the main aim is simply to rank treatments rather than to measure their effects accurately.

With splash-dispersed pathogens, a large proportion of the spores is carried in splash droplets that are deposited within $1 \mathrm{~m}$ of the source (Fitt \& McCartney, 1986). For such pathogens it is often assumed that inter-plot interference is of little consequence in plots of conventional size. However, if plots are contiguous or separated only by narrow paths, dispersal over such short distances may nevertheless be sufficient to carry spores between plots. The numbers of spores that are transferred between plots in this way may be small in relation to total production but may be significant if sources within the recipient plots are absent or few. In the United Kingdom, the 
majority of cereal crops are sown in autumn, and many of them in September. Such early-sown crops are not harvested until 10-11 months after sowing and they remain in the seedling and tillering stages, when they are relatively inefficient in filtering spores from the air, for up to 6 months. Thus, even if individual dispersal events move few spores between plots, they can be expected to occur frequently, so, with secondary spread within the recipient plots, the cumulative effects may be substantial.

In this paper we describe three experiments in harvest years 1981 and 1982 that tested the effects of inoculation treatments and fungicides on the development of leaf blotch (caused by the splash-dispersed pathogen Rhynchosporium secalis) in plots of winter barley. All three experiments were of serially balanced design so that we could compare disease development in similarly treated plots with differently treated neighbours. The direct effects of treatments in these experiments, plus two others, have been described in a previous paper (Jenkyn et al. 1989). One of these additional experiments (in harvest year 1980) was also of balanced design but as it was grazed by rabbits, few disease data were obtained during winter and early spring. It has, therefore, been excluded from the present paper in which we confine our attention to the inter-plot effects. Disease gradients away from single inoculated plots of winter barley were measured in 1981 and 1982 and are also described.

\section{MATERIALS AND METHODS}

The balanced experiments used designs (Dyke \& Shelley, 1976) similar to those used in earlier experiments with powdery mildew (Erysiphe graminis f.sp. hordei) on spring barley (Jenkyn et al. 1979; Jenkyn, Dyke \& Todd, 1983). A feature of these designs is that plots of any one treatment have as leftand right-hand neighbours every possible ordered pair of treatments (excluding the treatment applied to the plot itself), with each pair occurring only once per replicate.

The treatments tested, and the principal measurements, are summarized below but further details of these and of the husbandry of the experiments are provided in the paper by Jenkyn et al. (1989) which describes the direct effects of the treatments. To avoid confusion, we number the experiments as in the previous paper. All plots were sown with winter barley cv. Maris Otter.

In Expt 2 (1981; dates refer to year of harvest), plots of winter barley sown on 27 September were either inoculated with rhynchosporium-infected straw or sprayed with the fungicide prochloraz on 22 December or 3 April or on both dates. These four treatments were tested in a single replicate balanced design (i.e. 36 plots + dummy plots at each end of the row) that was orientated so that neighbours were to the east and west.

In Expt 3 (1981), one treatment tested winter barley sown on 27 September, that was inoculated with infected straw as in Expt 2. Other plots were sown on 19 February and were either unsprayed or sprayed with prochloraz on 3 April or on both 3 April and 21 May. The design and orientation of the experiment were the same as for Expt 2.

In Expt 4 (1982) plots that were inoculated with infected straw were compared with others that were sprayed with prochloraz on 1 February or 22 March or on both dates, and with a fifth treatment that was neither inoculated nor sprayed. Because the available site was not large enough to accommodate the minimum number of plots needed to test the five treatments in a single replicate balanced design $(80+2$ dummies) in a single line, the plots were arranged in two parallel rows, $26 \mathrm{~m}$ apart. The experiment was sown on 15 October and the orientation was such that neighbours were to the north-east and south-west.

Leaf diseases were assessed using standard area diagrams (Anon. 1976) to estimate the percentage area affected on the leaves of 10 shoots taken at random from each side of every plot. To provide another measure of amounts of leaf blotch in the plots, plants were sampled, usually from the discard areas along the sides of plots, and washed in water; numbers of spores of $R$. secalis in the water were estimated using a haemocytometer slide. In 1981, the plants from the two sides of each plot were bulked to form one sample per plot. In 1982 the plants from the two sides constituted separate samples and were separately counted (except on the last date in that year when shoots were sampled from the two ends of the plots and then bulked to form one sample per plot). On some occasions total leaf blotch lesions on the sampled plants were also counted before washing.

In addition pots of winter barley seedlings (cv. Maris Otter, grown in a soil-less compost) were periodically exposed in the centres of the plots. These were intended to monitor inoculum moving within and between plots rather than amounts of disease in the crop and so these data were not reported in the previous paper. There were usually five or six seedlings in a $7.5 \mathrm{~cm}$ diameter pot. After sowing, the pots were kept in a cool glasshouse until the seedlings emerged and were then transferred outside to harden off. During exposure, the pots containing the seedlings were placed in empty pots that had been sunk in the ground so that, early in crop growth, the seedlings were at a similar height to the surrounding crop. Periods of exposure ranged from a few days to several weeks, largely depending on the weather. Seedlings were, for example, changed more frequently during periods of mild wet weather, when spore dispersal and infection were expected to be favoured, than during cold, dry weather, when they were not. Damage to 
seedlings during very cold weather meant that some tests had to be abandoned. After exposure, seedlings were returned to a cool glasshouse until visible symptoms had developed when the lesions were counted. During symptom development, ethirimol sprays were applied as necessary to control powdery mildew that might otherwise have obscured symptoms of leaf blotch.

In both 1981 and 1982, extra plots of Maris Otter winter barley (with the same dimensions as other plots in the respective years), inoculated with rhynchosporium-infected straw, were sown in the surrounding crop (cvs Athene and Igri, respectively) and used to measure infection gradients. In 1981, gradients were also measured using a further inoculated plot of Maris Otter winter barley that was surrounded by ca. $8 \mathrm{~m}$ of Maris Otter that was neither inoculated nor sprayed with fungicides. To measure infection gradients, pots of seedlings (see above) were exposed at distances of $0,25,50,75,100,150$ and $250 \mathrm{~cm}$ from the eastern and north-eastern (i.e. usually downwind) edges of the Maris Otter plots, respectively, in the 2 years. Numbers of pots exposed at each distance on each occasion were $2,4,4,6,6,8$ and 10 , respectively, in 1981 and $4,6,8,10,12,16$ and 24 , respectively, in 1982. The results presented are based on six periods of exposure, between December and April, in 1981 and 12 periods of exposure, between November and March, in 1982 but for simplicity we present geometric means of counts for two (1981) or three (1982) successive periods.

\section{Data analysis and interpretation}

For the statistical analysis of all lesion and spore counts, a logarithmic transformation to the base $e$ was used. For the analysis of leaf disease data, mean percentages $(P \%)$ were calculated for each sample and a logit transformation used:

$$
0.5 \log _{\mathrm{e}}[(P \%+0.05) /(100.05-P \%)] \text {. }
$$

The standard errors shown in the tables and figures apply to the quoted transform data. The counts and percentage values shown were obtained by back transformation.

In this paper the analyses of the results are based on the treatment structure

$$
T+T . L+T . R[=T /(L+R)]
$$

where $T$ represents the direct effects of treatments to plots and $L, R$ the effects of treatments to left- and right-hand neighbours, respectively (Wilkinson \& Rogers, 1973). The interaction T.L.R was used as the estimate of error. For comparison we also refer to the analyses assuming randomized block designs used previously (Jenkyn et al. 1989). These blocks analyses suggested that there was substantial variation across the sites of these experiments and, for Expts 3 and 4, when neighbour analysis was used, covariance adjustment using four-term Fourier series (two sine and two cosine terms) significantly improved precision. For these experiments we present adjusted yield results. There was little evidence to suggest that positional variation significantly affected the disease data and for these the unadjusted analyses were used.

The experiments described generated many data, most of which can be grouped into large sets of related variates, e.g. spore counts on successive dates. The data in such sets have been used to examine the consistency of the neighbour effects (regardless of their significance in individual analyses) and, by averaging over all variates within a set, to estimate the relative magnitude of the direct and neighbour effects. For this purpose we have restricted our attention to those treatment-contrasts that were expected to show the largest effects. Thus we have usually compared the difference between straw-inoculated and twicesprayed plots (the direct effect) with their contrasting effects as neighbours on each of the remaining two (Expts 2 and 3) or three (Expt 4) treatments. For the variates within these data sets we have also compared the residual mean squares obtained when the experiments were analysed using the two methods described above.

To simplify comparisons between variates within a set (e.g. spore counts on successive dates) we have usually imposed the same treatment structure throughout. Thus, for most variates it has been assumed that all fungicide treatments had been applied even for those measurements that were made before the actual dates of treatment. This ensures that the degrees of freedom for the chosen contrasts in any one experiment are constant throughout. It also provided the opportunity to detect gross differences between plots in the early stages which, if they persisted, might have been spuriously attributed to the treatments that were subsequently applied. However, selected variates were also analysed using reduced treatment structures to take account of the absence of certain treatments (e.g. all fungicide-treated plots were identical until the first fungicide sprays were applied). Data from these latter analyses are mostly not presented here but from them we were able to confirm that no appreciable bias was introduced by using the full treatment structure throughout.

\section{RESULTS}

\section{Experiment 2 (1981)}

\section{Effects of neighbouring treatments on diseases}

The numbers of leaf blotch infections that developed on seedlings exposed in the plots, on 14 occasions between October and May, showed highly significant differences between treatments on all except the first and last two occasions. In spite of this, however, only two of these individual analyses provided any evidence for effects of neighbouring treatments. In contrast, numbers of spores washed from plants sampled on 

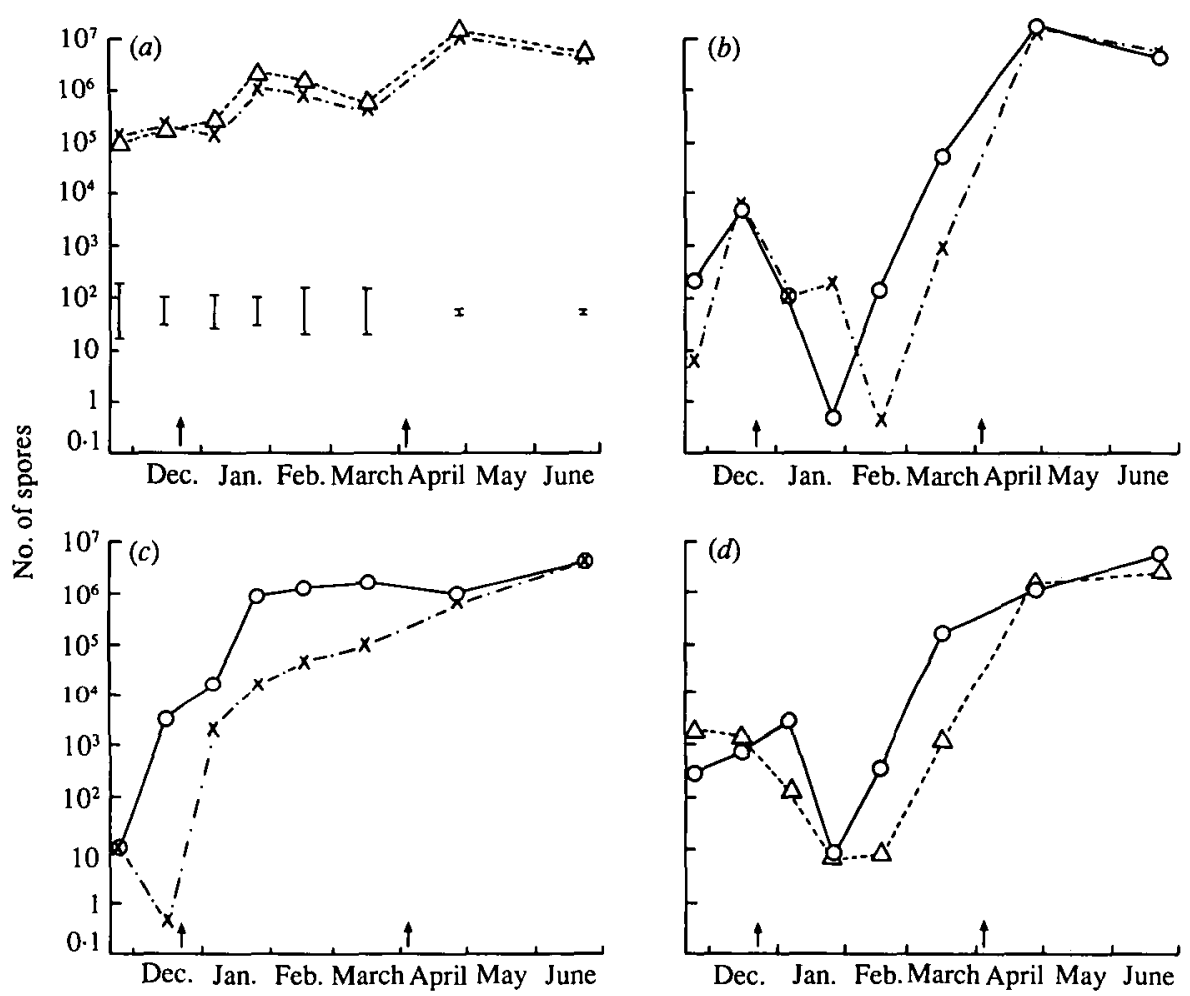

Fig. 1. Average numbers of $R$. secalis spores per plant (last date: numbers of spores per shoot) in plots of Maris Otter winter barley that were either inoculated $(a)$ or sprayed with prochloraz on 22 December $(b), 3$ April $(c)$ or 22 December and 3 April $(d)$ with contrasting neighbours to the west, namely, inoculated $(O-O)$; sprayed with prochloraz on 22 December $(\triangle \cdots-\cdots)$; sprayed with prochloraz on 22 December and 3 April $(\times-\cdot-\cdot-\cdot x)$. The bars represent the standard errors of the means on each date and the arrows indicate when the fungicide sprays were applied (Expt 2, 1981).

eight dates between November and June showed significant effects of treatments on every date and significant effects of neighbouring treatments on five of the eight. There were effects of both eastern and western neighbours but, overall, it was those to the west that had the largest effects. Figure 1 illustrates the effects of contrasting treatments to western neighbours on each of the treatments tested. Not surprisingly, the inoculated plots, which had severe leaf blotch for much of the season, were relatively little affected by neighbouring treatments (Fig. 1a). In contrast, those that received only a single spray were very much affected. Reinfection of those sprayed in December, for example, was much faster where the western neighbour was inoculated than where it was sprayed in both December and April (Fig. 1b). These same treatments applied to neighbouring plots similarly meant that plots sprayed only in April had very different amounts of disease when that spray was applied (Fig. 1c). Even the twice-sprayed plots were affected by neighbouring treatments, as illustrated by Fig. $1 d$. Indeed, in late June all plots except the twicesprayed had much disease and it was principally among the twice-sprayed plots that neighbouring treatments had significant effects. There were, for example, more than twice as many spores where the western neighbour was inoculated than where the western neighbour was uninoculated and had been sprayed with prochloraz in December (Fig. 1d).

Estimates of disease severity in November and December were obtained by counting lesions on the plants sampled for counting spores. However, the data were variable and provided no evidence for effects of neighbouring treatments even though numbers of spores in December did show significant effects. Average amounts of leaf blotch in the plots on 22 April similarly showed no significant effects of neighbouring treatments. However, separate analyses of the data for the two sides of each plot showed that leaf blotch on second youngest leaves from the eastern sides of plots was significantly affected by eastern neighbours while that on leaves from the western sides of plots was significantly affected by western neighbours. Predictably, the disease was usually most severe where the adjacent neighbour had been inoculated. Arisong the plots sprayed oniy in 
Table 1. Mildew (percentage area affected) on third youngest leaves sampled on 22 April from plots given different treatments and with differently treated neighbours to the west* (Expt 2, 1981)

\begin{tabular}{|c|c|c|c|c|}
\hline \multirow[b]{2}{*}{$\begin{array}{l}\text { Plot } \\
\text { treatment }\end{array}$} & \multicolumn{4}{|c|}{ Treatment to western neighbour } \\
\hline & Inoculated & $\begin{array}{l}\text { Sprayed } \\
22 \text { Dec. }\end{array}$ & $\begin{array}{l}\text { Sprayed } \\
3 \text { April }\end{array}$ & $\begin{array}{c}\text { Sprayed } \\
22 \text { Dec. }+3 \text { April }\end{array}$ \\
\hline Inoculated & - & $-0.94(13.3)$ & $-0.99(12.1)$ & $-0 \cdot 99(12 \cdot 1)$ \\
\hline Sprayed 22 Dec. & $-0.63(21.9)$ & - & $-0.25(37.9)$ & $-0.38(32.0)$ \\
\hline Sprayed 3 April & $-1.28(7.2)$ & $-0.94(13.3)$ & - & $-0.91(13.9)$ \\
\hline Sprayed 22 Dec. +3 April & $-1 \cdot 10(10.0)$ & $-0.83(15.9)$ & $-0.93(13.5)$ & - \\
\hline S.E. $($ D.F. $=16)$ & \multicolumn{4}{|c|}{0.089} \\
\hline
\end{tabular}

* Data are logit transform values of the means of separate assessments on the eastern and western sides of plots with, in parentheses, the corresponding percentage values obtained by back transformation.

December, for example, amounts of leaf blotch on second youngest leaves from the western sides averaged 5.1 and $8.4 \%$, respectively, where the western neighbour was twice sprayed or inoculated; corresponding values for the eastern sides of plots with similarly contrasting neighbours to the east were 3.5 and $8.9 \%$, respectively.

When the disease was next assessed, on 20 May, there were again significant effects of neighbouring treatments but, on this occasion, the disease was often less severe where neighbours, and especially those to the west, were inoculated and unsprayed than where they were twice sprayed. Thus, in plots sprayed only in December, average amounts of leaf blotch on second youngest leaves taken from both sides of the plots were 0.3 and $1.6 \%$ where the western neighbour was inoculated or twice sprayed, respectively; corresponding values for third youngest leaves were 4.9 and $8.8 \%$, respectively.

At the final assessment on 22 June, effects of neighbouring treatments on leaf blotch were no longer significant but it is possible that relatively small differences might have been obscured by mildew which was then prevalent.

When mildew was first assessed, in mid-February, it was significantly affected by treatments but not by treatments to neighbouring plots. On 22 April, however, mildew on third youngest leaves was significantly affected by treatments to western neighbours. Among the sprayed plots, the disease was consistently less severe where the western neighbour had been inoculated with rhynchosporium-infected straw than where it had been sprayed (Table 1), reflecting the direct effects of treatments previously described (Jenkyn et al. 1989). This was true even where the western neighbour had been sprayed in December and April and where the disease was, on average, no more severe than in the straw-inoculated plots. However, mildew was very severe in plots sprayed only in December so it can be assumed that the twice-sprayed plots were also potent sources of inoculum before the second spray was applied on 3 April. In May and June, effects of neighbouring treatments on mildew were small and not significant.

Brown rust on 22 June was also affected by neighbouring treatments and especially by those to the west. Like mildew on 22 April, it was consistently less severe where the western neighbour had been inoculated with rhynchosporium-infected straw than where it had been sprayed, again reflecting the direct effects. Among the twice-sprayed plots, for example, amounts of rust on second youngest leaves averaged $1.5,2.9$ and $2.3 \%$, respectively, where the western neighbour had been inoculated, or sprayed with prochloraz in December or April.

In Table 2 we compare, for groups of related variates, the mean effects of two selected treatments on the plots to which they were applied (direct effects) with the effects of the same treatments as neighbours of the remaining two (neighbour effects). The selected treatments were those expected to show the greatest difference, namely, inoculation with rhynchosporiuminfected straw $v$. two sprays of prochloraz. It can be seen that for the eight variates representing numbers of spores washed from sampled plants, the average neighbour effect was equivalent to $22.4 \%$ of the direct effect (on the transform scale). Even this is probably a somewhat conservative estimate because, as already described, it was principally the twice-sprayed plots that were affected by neighbouring treatments at the end of the season and these effects are not taken into account in deriving this value. Furthermore, it represents the mean effect of eastern and western neighbours, and the evidence suggests that western neighbours had larger effects than did eastern neighbours. 
Table 2. Summaries of the average effects of selected treatments on the plots to which they were applied and on neighbouring plots, and relative efficiencies of analyses in which effects of neighbouring treatments were recognized or were not (Expt 2, 1981)

\begin{tabular}{|c|c|c|c|c|}
\hline Observations ... & $\begin{array}{l}\text { Leaf blotch } \\
\text { (number of lesions) } \\
\text { on exposed plants }\end{array}$ & $\begin{array}{c}\text { Number of } \\
R . \text { secalis spores } \\
\text { on sampled plants }\end{array}$ & $\begin{array}{l}\text { Leaf blotch } \\
\text { (\% leaf area) }\end{array}$ & $\begin{array}{c}\text { Mildew } \\
\text { (\% leaf area) }\end{array}$ \\
\hline $\begin{array}{l}\text { Number of variates } \\
\text { in data set }\end{array}$ & 14 & 8 & $18^{*}$ & $20^{*}$ \\
\hline Mean direct effect $\dagger$ & $\begin{array}{l}+2 \cdot 02 \\
(7 \cdot 5: 1)\end{array}$ & $\begin{array}{l}+6 \cdot 25 \\
(516: 1)\end{array}$ & $\begin{array}{l}+0.97 \\
(6 \cdot 8: 1)\end{array}$ & $\begin{array}{l}0 \cdot 00 \\
(1 \cdot 0: 1)\end{array}$ \\
\hline Mean neighbour effect $\dagger$ & $\begin{array}{l}+0 \cdot 17 \\
(1 \cdot 2: 1)\end{array}$ & $\begin{array}{l}+1 \cdot 40 \\
(4 \cdot 1: 1)\end{array}$ & $\begin{array}{l}-0.01 \\
(0.99: 1)\end{array}$ & $\begin{array}{l}-0.05 \\
(0.91: 1)\end{array}$ \\
\hline $\begin{array}{l}\text { Neighbour effect as } \\
\text { percentage of direct effect }\end{array}$ & $+8.2 \%$ & $+22.4 \%$ & $-0.8 \%$ & $(-) \S$ \\
\hline $\begin{array}{l}\text { Mean value of RMS } \\
\text { (blocks)/RMS (neighbours) } \ddagger\end{array}$ & $1 \cdot 14$ & 1.59 & 1.63 & 0.99 \\
\hline
\end{tabular}

* Includes six derived variates representing the means of the separate assessments on the two sides of the plots. $\dagger$ Effects are calculated from the transformed data and represent the difference between inoculation with rhynchosporiuminfected straw and spraying twice with prochloraz, in December and April.

¥ Residual mean squares (RMS) derived from analyses assuming a block structure ( 9 blocks of 4 plots), in which effects of neighbouring treatments are ignored, and analyses which recognise the imposed balance, and hence effects of neighbouring treatments, but take no account of blocks.

$\S$ No value has been entered here because the denominator is very small and the estimate consequently unreliable.

Data from exposed seedlings provided much less evidence of significant neighbour effects, as described above, but over the 14 variates the mean neighbour effect was nevertheless positive and equivalent to $8.2 \%$ of the direct effect.

Altogether there were 18 variates measuring severity of leaf blotch. Like all other variates they were derived from the same plots sampled on successive occasions but there is further correlation within this group because each sample was used to derive more than one variate (i.e. disease severity on different leaves). On average, effects of neighbouring treatments on severity of leaf blotch were very small (Table 2); however, this is misleading because the results for each of the three dates were very different. Thus considering only whole-plot data (i.e. the means of the separate assessments on the eastern and western sides of the plots), the average neighbour effect for the two leaves assessed on 22 April was large and positive (15.8\% of the direct effect), on 20 May it was large and negative (-22.4\% of the direct effect which was positive), while on 22 June it was positive but very small $(4 \cdot 7 \%)$.

The mildew data also show a neighbour effect that was, on average, very small (Table 2 ) but, again, this conceals marked differences between successive dates. In February, the direct effect of the prochloraz spray applied in December was relatively large and the neighbour effect, which operated in the same direction, was equivalent to $17.5 \%$ of the direct effect. By April, the direct effect was much smaller but the neighbour effect was relatively much larger $(159.8 \%$ of the direct effect). However, on this occasion both the direct and neighbour effects were of opposite sign to the effects detected in February (i.e. sprayed plots and those adjacent to sprayed plots had more mildew than unsprayed plots) so in calculating the mean effects, the data for these two dates cancel one another. Finally, in May and June, both direct and neighbour effects were very small.

The data described above were derived from analyses that recognized the balanced structure of the designs and took account of the effects of treatments applied to neighbouring plots. For comparison, most variates were also analysed using a blocks $\times$ treatments structure ( 9 blocks of 4 plots) which ignored the effects of neighbouring treatments. Most of the blocks analyses on variates summarized in Table 2 provided little evidence of significant differences between blocks. Typically, the residual mean squares (RMS) from these blocks analyses were much larger than those derived from the neighbour analyses, illustrating the potential gains to be achieved by recognizing the effects of treatments to neighbouring plots. Analyses of spore counts, for example, had residual mean squares that were, on average, more than $50 \%$ greater when effects of neighbouring treatments were ignored than when they were recognized. The leaf blotch data, in which the mean neighbour effect was very small because there were 
opposite effects on different dates, similarly show smaller residual mean squares when neighbour effects were recognized than when they were ignored. By contrast, there was no overall benefit in using the neighbour analysis for the mildew data, reflecting the generally much smaller effects of neighbouring treatments on this disease than on leaf blotch. Nevertheless there was a clear advantage in using this analysis for the April mildew data, which showed the largest effect of neighbouring treatments on this disease (RMS (blocks)/RMS (neighbours) $=1 \cdot 25$ )

\section{Effects of neighbouring treatments on growth and yield}

Seedlings sampled from the uninoculated plots (sprayed or unsprayed) in mid-March were significantly smaller where the western neighbour had been inoculated (mean $0.15 \mathrm{~g}$ per plant) than where it had not (mean $0.19 \mathrm{~g}$ per plant). Lodging was very variable across the site and a close examination of the data showed that a significant neighbour effect on lodging was mostly explained by two 'treatments' (i.e. combinations of treatments to a plot and its neighbours). These were allocated to six plots which, by chance, were all located within a space of nine plots in that part of the experiment that was most severely affected by lodging. We therefore consider this to be a spurious result. Analyses of both grain yields and 1000-grain weights also suggested that there were effects of treatments to neighbouring plots. However, there were clear correlations with the lodging data (much the smallest yields and 1000-grain weights being obtained from those plots that were most severely affected by lodging) so these effects must also be considered spurious.

\section{Experiment 3 (1981)}

\section{Effects of neighbouring treatments on diseases}

Individual analyses of numbers of leaf blotch infections that developed on seedlings exposed on different occasions in the spring-sown plots, either before or after these plots were sown, provided little evidence to suggest that there was much effect of proximity to autumn-sown plots, except on one occasion, despite the fact that the latter were severely diseased and of ten potent sources of inoculum. The one exception was the period 25 March-2 April, just before symptoms of leaf blotch were first seen in the springsown plots on 6 April. On that occasion, seedlings exposed in the spring-sown plots developed significantly more lesions where the neighbour was autumn-sown than where it was spring-sown, whether these contrasting neighbours were to the east $(1.8 v$. 0.8 lesions per pot) or to the west $(2.2 v .0 .7$ lesions per pot). The next and final test, which covered the period 15-21 May, again detected effects of treatments to plots but not of treatments to neighbouring plots.
Numbers of spores washed from plants sampled on 5 May similarly showed only small and not significant effects of neighbouring treatments. In contrast, comparable data for 29 June showed significant effects of neighbouring treatments to both the east and west. Generally, it was the sprayed, spring-sown plots that were most affected, yielding many more spores where the neighbouring plot was autumn-sown than where it was spring-sown, and especially where the neighbouring spring-sown plot had been sprayed with prochloraz (Table 3 ).

In this experiment, however, it was symptoms of leaf blotch on the leaves that apparently provided the best evidence for effects of neighbouring treatments. On 23 April areas affected on second youngest leaves were little affected by neighbouring treatments, but this was perhaps not surprising because symptoms were largely confined to the older leaves, many of which had begun to senesce and were, therefore, not assessed. However, arbitrary scores indicating the ease with which symptoms could be found, and their relative abundance, showed that in the spring-sown plots the disease was more severe where the western neighbour was autumn-sown than where it was spring-sown. Leaf areas affected by leaf blotch on 20 May were also affected by western neighbours but on that occasion it was principally the unsprayed, springsown plots that showed the effect, and mostly in the amounts of disease on their western sides. By 23 June there were effects of both eastern and western neighbours which, on second youngest leaves from the spring-sown plots, were large enough to be significant in the whole-plot data (i.e. the means of the separate assessments on the eastern and western sides of plots); not surprisingly, however, effects of eastern neighbours were especially marked on the eastern sides of adjacent plots and those of western neighbours on the western sides. Similar results were obtained on 14 July. Because effects of eastern and western neighbours were broadly similar, we have in Table 4 presented only the latter. On both dates leaf blotch in the unsprayed spring-sown plots was again more severe where the neighbouring plot was autumn-sown than where it was spring-sown, but similar effects of neighbouring treatments on the reinfection of the sprayed, spring-sown plots were also apparent.

Effects of neighbouring treatments on powdery mildew were generally small and not significant, reflecting relatively small and short-lived effects of the fungicide sprays on this disease.

To quantify further the interactions between plots we again compared direct and neighbour effects averaged over treatments and dates. During the first nine occasions that seedlings were exposed in the plots there was no crop in the spring-sown plots, either because the seed had not been sown or because the seedlings had not emerged. Over this period (November-March), the average effect of the 
Table 3. Mean numbers of spores of $\mathrm{R}$. secalis washed from barley shoots sampled from sprayed, spring-sown plots with differently treated neighbours on 29 June 1981 (Expt 3, 1981)*

\begin{tabular}{|c|c|c|c|c|}
\hline \multirow[b]{3}{*}{$\begin{array}{l}\text { Plot treatment } \\
\text { (all spring-sown) }\end{array}$} & \multicolumn{4}{|c|}{ Treatment to neighbouring plot } \\
\hline & \multirow{2}{*}{$\begin{array}{l}\text { Autumn-sown } \\
\text { Inoculated }\end{array}$} & \multicolumn{3}{|c|}{ Spring-sown } \\
\hline & & Unsprayed & $\begin{array}{l}\text { Sprayed } \\
3 \text { April }\end{array}$ & $\begin{array}{c}\text { Sprayed } \\
3 \text { April }+21 \text { May }\end{array}$ \\
\hline \multicolumn{5}{|c|}{ Eastern neighbours } \\
\hline Sprayed 3 April & $13 \cdot 22(55)$ & $12 \cdot 59(29)$ & - & $12 \cdot 38(24)$ \\
\hline Sprayed 3 April + 21 May & $11 \cdot 42(9 \cdot 1)$ & $10 \cdot 62(4 \cdot 1)$ & $10 \cdot 17(2 \cdot 6)$ & - \\
\hline \multicolumn{5}{|c|}{ Western neighbours } \\
\hline Sprayed 3 April & $13 \cdot 28(58)$ & $12 \cdot 84(38)$ & - & $12.07(17)$ \\
\hline Sprayed 3 April +21 May & $11 \cdot 54(10)$ & $9 \cdot 94(2 \cdot 1)$ & $10 \cdot 73(4 \cdot 6)$ & - \\
\hline S.E. $($ D.F. $=16)$ & \multicolumn{4}{|c|}{0.212} \\
\hline
\end{tabular}

* Data are $\log _{\mathrm{e}}$ transform values with, in parentheses, the corresponding counts $\left(\times 10^{-4}\right)$ obtained by back transformation.

Table 4. Leaf blotch (percentage area affected) on second youngest leaves in spring-sown plots with differently treated neighbours to the west, on 23 June and 14 July 1981 (Expt 3, 1981)*

\begin{tabular}{|c|c|c|c|c|}
\hline \multirow[b]{3}{*}{$\begin{array}{l}\text { Plot treatment } \\
\text { (all spring-sown) }\end{array}$} & \multicolumn{4}{|c|}{ Treatment to western neighbour } \\
\hline & \multirow{2}{*}{$\begin{array}{l}\text { Autumn-sown } \\
\text { Inoculated }\end{array}$} & \multicolumn{3}{|c|}{ Spring-sown } \\
\hline & & Unsprayed & $\begin{array}{l}\text { Sprayed } \\
3 \text { April }\end{array}$ & $\begin{array}{c}\text { Sprayed } \\
3 \text { April }+21 \text { May }\end{array}$ \\
\hline \multicolumn{5}{|c|}{23 June 1981} \\
\hline Unsprayed & $-1.23(7.8)$ & - & $-1.45(5.2)$ & $-1.52(4 \cdot 5)$ \\
\hline Sprayed 3 April & $-1 \cdot 71(3 \cdot 2)$ & $-2 \cdot 21(1 \cdot 2)$ & - & $-2 \cdot 13(1.4)$ \\
\hline Sprayed 3 April + 21 May & $-2 \cdot 35(0 \cdot 9)$ & $-3.09(0.2)$ & $-2 \cdot 85(0.3)$ & - \\
\hline S.E. $($ D.F. $=12)$ & \multicolumn{4}{|c|}{0.155} \\
\hline & \multicolumn{4}{|c|}{14 July 1981} \\
\hline Unsprayed & $-0.70(19.7)$ & - & $-1.19(8.5)$ & $-0.93(13.4)$ \\
\hline Sprayed 3 April & $-1 \cdot 18(8 \cdot 7)$ & $-1.45(5.3)$ & - & $-1.46(5 \cdot 1)$ \\
\hline Sprayed 3 April +21 May & $-2 \cdot 02 \quad(1 \cdot 8)$ & $-2.04(1.7)$ & $-2 \cdot 30(1 \cdot 0)$ & - \\
\hline S.E. $($ D.F. $=12)$ & \multicolumn{4}{|c|}{0.078} \\
\hline
\end{tabular}

* Data are means of separate assessments on the eastern and western sides of plots and are logit transform values with, in parentheses, the corresponding percentage values obtained by back transformation.

autumn-sown, inoculated barley (i.e. autumn-sown, inoculated $v$. 'spring-sown') as a neighbouring treatment was only $5.0 \%$ of its direct effect, confirming the results of the individual analyses. However, in the last three tests, which covered the period after the spring-sown barley had emerged and included one test done after the April spray was applied, the average effect of the autumn-sown, inoculated barley as a neighbouring treatment was relatively larger, being $16.8 \%$ of its direct effect.
Differences in morphology between the autumnand spring-sown barley meant that it was often inappropriate to make direct comparisons between them. The neighbour effects that we quote below are, therefore, expressed as percentages of the direct effects of sprays on spring-sown crops (i.e. unsprayed $v$. once, later twice, sprayed). Numbers of spores, which were not counted until leaf blotch was well established in the spring-sown plots, showed relatively large effects of neighbouring treatments. Thus on 
5 May, the mean neighbour effect (autumn-sown, inoculated $v$. spring-sown, once-sprayed) on the unsprayed, spring-sown barley was $15.6 \%$ of the specified direct effect. In June, after the second spray had been applied, the mean neighbour effect (autumnsown, inoculated $v$. spring-sown, twice-sprayed) on the unsprayed and once-sprayed barley was $19.8 \%$ of the specified direct effect. Symptoms on the leaves showed similarly large interactions with a mean neighbour effect over all variates (representing four assessment dates) equivalent to $34.1 \%$ of the direct effect.

As in Expt 2, analyses that recognized the effects of neighbouring treatments had residual mean squares that were often much smaller than those derived from analyses assuming a blocks $\times$ treatments structure in which the effects of neighbouring treatments were ignored. Thus the calculated ratios (RMS (blocks)/ RMS (neighbours)) for spore counts (two variates) and for leaf blotch assessments (24 variates, including eight derived variates) averaged 1.75 and 1.78 , respectively. In contrast, analyses of data from the exposed plant tests (12 variates) and of mildew data (27 variates, including nine derived variates), both of which provided much less evidence for effects of neighbouring treatments, showed no advantage in using the neighbour analyses with mean ratios of 0.98 and 0.85 , respectively.

\section{Effects of neighbouring treatments on growth and yield}

None were detected.

\section{Experiment 4 (1982)}

\section{Effects of neighbouring treatments on diseases}

There were highly significant effects of treatments on the numbers of leaf blotch lesions that developed on exposed seedlings on each of the nine occasions that tests were done between December and May but only the three tests done between 21 January and 10 March showed significant effects of neighbouring treatments. However, numbers of spores washed from sampled plants again provided convincing evidence for such effects. Thus there were significant effects of treatments and of treatments to south-western neighbours on each of the six dates that samples were taken between December and May. On two of these dates (in March and April) it was only in data for southwestern sides of plots that effects of neighbouring treatments were detected but on the remaining four dates the effects were large enough to be apparent in the whole-plot data (i.e. the means of the separate counts done on samples from the south-western and north-eastern sides of the plots). Only the samples taken on 25 June showed no evidence for effects of neighbouring treatments although the direct effects of treatments on that date were again highly significant.
Figure 2 shows the effects of contrasting treatments to south-western neighbours on four of the five treatments tested. Data for the inoculated plots have been omitted because, as in the previous year, they were relatively little affected by neighbouring treatments. Comparing different treatments on individual dates reveals some inconsistency in the data and especially in those for December and January. These dates precede the application of any fungicide sprays so that results for the four treatments shown should have been identical. However, on these dates leaf blotch was still slight and samples yielded relatively few spores and there was, as might be expected, greater variation among these data than among those obtained on all subsequent sampling dates. Nevertheless, analyses using a reduced treatment structure showed that on both dates significantly more spores were obtained from plots with an inoculated than with an uninoculated south-western neighbour. Similar effects of inoculated neighbours were apparent on all subsequent dates, regardless of plot treatment, so agreeing with the results obtained in 1981 (Fig. 1).

Numbers of lesions caused by $R$. secalis were counted on plants sampled from the plots in December, January and February. These data showed significant effects of treatments on the disease but little evidence to suggest that it was affected by neighbouring treatments, except in February when there was strong evidence that disease on the northeastern sides of plots was increased if the northeastern neighbour had been inoculated. Generally, however, these data were, as in 1981, very variable, probably reflecting the difficulties experienced in identifying and counting individual lesions, especially when the leaves were beginning to senesce. Leaf areas affected by the disease in June, especially in the sprayed plots, were, however, significantly affected by neighbouring treatments and especially by those to the south-west (Table 5). Predictably, the disease was usually more severe where the south-western neighbour had been inoculated than where it had been sprayed with prochloraz.

Mildew on second youngest leaves in June was also significantly affected by treatments to south-western neighbours but with this disease it seemed to be the uninoculated, unsprayed plots that were most affected. In these, mildew was most severe where the southwestern neighbour had been sprayed with prochloraz in February $(27.7 \%)$ or February and March $(30.3 \%)$, much less severe where the south-western neighbour had been sprayed only in March $(17.7 \%)$ and least severe where the south-western neighbour had been inoculated $(13.7 \%)$. These results are consistent with the direct effects of these treatments. The sprayed plots showed smaller but generally similar effects of neighbouring treatments. In contrast, however, the inoculated plots inexplicably had less mildew where the south-western neighbour had been sprayed in 


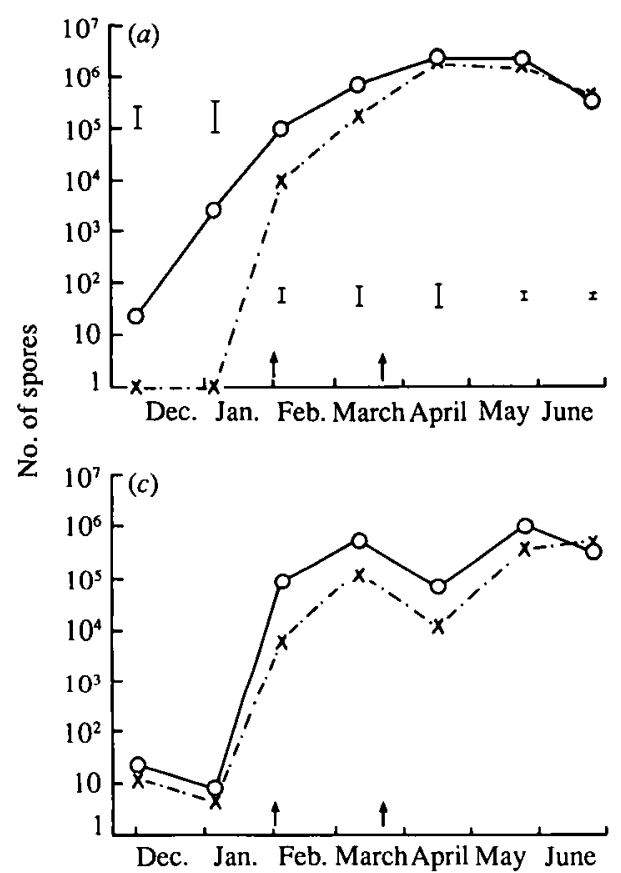

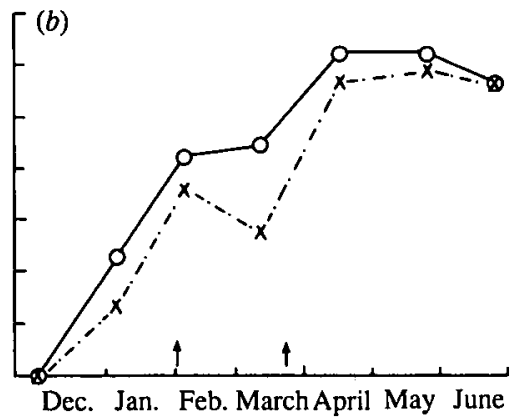

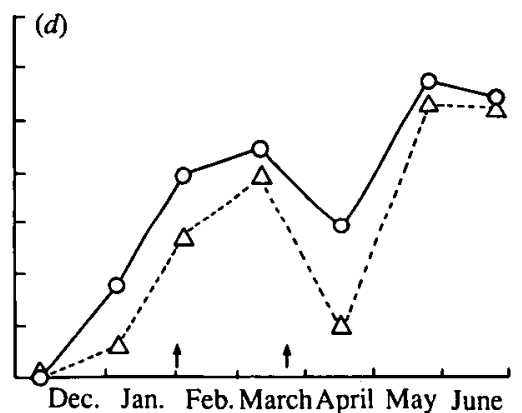

Fig. 2. Average numbers of $R$. secalis spores per plant (last two dates: numbers of spores per shoot) in plots of Maris Otter winter barley that were either uninoculated and unsprayed $(a)$ or sprayed with prochloraz on 1 February $(b), 22$ March $(c)$ or 1 February and 22 March $(d)$ with contrasting neighbours to the south-west, namely, inoculated $(\mathrm{O}-\mathrm{O})$; sprayed with prochloraz on I February $(\Delta \cdots-\Delta)$; sprayed with prochloraz on I February and 22 March $(x-\cdot-\cdot--x)$. The bars represent the standard errors of the means on each date and the arrows indicate when the fungicide sprays were applied (Expt 4, 1982).

Table 5. Leaf blotch (percentage area affected) on second youngest leaves sampled on 17 June from sprayed plots with differently treated neighbours to the south-west* (Expt 4, 1982)

\begin{tabular}{|c|c|c|c|c|}
\hline \multirow[b]{2}{*}{$\begin{array}{l}\text { Plot } \\
\text { treatment }\end{array}$} & \multicolumn{4}{|c|}{ Treatment to south-western neighbour } \\
\hline & Inoculated & $\begin{array}{l}\text { Sprayed } \\
\text { I Feb. }\end{array}$ & $\begin{array}{c}\text { Sprayed } \\
22 \text { March }\end{array}$ & $\begin{array}{c}\text { Sprayed } \\
1 \mathrm{Feb} .+22 \text { March }\end{array}$ \\
\hline Sprayed I Feb. & $-1 \cdot 34(6 \cdot 5)$ & - & $-1.53(4.5)$ & $-1 \cdot 70(3 \cdot 2)$ \\
\hline Sprayed 22 March & $-1 \cdot 17(8 \cdot 7)$ & $-1.46(5 \cdot 1)$ & - & $-1.61(3.8)$ \\
\hline $\begin{array}{l}\text { Sprayed } 1 \text { Feb. + } \\
22 \text { March }\end{array}$ & $\underbrace{-1 \cdot 73(3 \cdot 1)}$ & $-2 \cdot 12(1 \cdot 4)$ & $-2 \cdot 01(1 \cdot 8)$ & - \\
\hline S.E. (D.F. $=45)$ & \multicolumn{4}{|c|}{$0 \cdot 111$} \\
\hline
\end{tabular}

* Data are means of separate assessments on the north-eastern and south-western sides of plots and are logit transform values with, in parentheses, the corresponding percentage values obtained by back transformation.

February $(13.5 \%)$ or in February and March (15.5\%) than where it was untreated or sprayed only in March ( 22.5 and $23.1 \%$, respectively).

Table 6 shows, for sets of related variates, the mean neighbour effects of straw inoculum $v$. two sprays of prochloraz on the remaining three treatments, compared with their direct effects. Among the nine variates measuring numbers of lesions on exposed seedlings (representing nine periods of exposure) the average neighbour effect was $20.1 \%$ of the direct effect. Overall, south-western neighbours had much larger effects than did north-eastern neighbours (36.1 and $4.1 \%$ of the direct effects, respectively) but this seemed to change with time. Thus, between December 
Table 6. Summaries of the average effects of selected treatments on the plots to which they were applied and on neighbouring plots, and relative efficiencies of analyses in which effects of neighbouring treatments were recognized or were not (Expt 4, 1982)

\begin{tabular}{|c|c|c|c|c|c|}
\hline Observations ... & $\begin{array}{l}\text { Leaf blotch } \\
\text { (number of } \\
\text { lesions) on } \\
\text { exposed plants }\end{array}$ & $\begin{array}{l}\text { Leaf blotch } \\
\text { (number of } \\
\text { lesions) on } \\
\text { sampled plants }\end{array}$ & $\begin{array}{c}\text { Number of } \\
R . \text { secalis } \\
\text { spores on } \\
\text { sampled plants }\end{array}$ & $\begin{array}{l}\text { Leaf blotch } \\
\text { (\% leaf area) }\end{array}$ & $\begin{array}{c}\text { Mildew } \\
\text { (\% leaf area) }\end{array}$ \\
\hline $\begin{array}{l}\text { Number of variates } \\
\text { in data set }\end{array}$ & 9 & 9(3) & $19(6)$ & $6(2)$ & $6(2)$ \\
\hline Mean direct effect $\dagger$ & $\begin{array}{l}+2 \cdot 17 \\
(8 \cdot 7: 1)\end{array}$ & $\begin{array}{l}+1 \cdot 22 \\
(3 \cdot 4: 1)\end{array}$ & $\begin{array}{l}+5 \cdot 64 \\
(281: 1)\end{array}$ & $\begin{array}{l}+0 \cdot 59 \\
(3 \cdot 2: 1)\end{array}$ & $\begin{array}{l}-0 \cdot 03 \\
(0 \cdot 9: 1)\end{array}$ \\
\hline Mean neighbour effect $\dagger$ & $\begin{array}{l}+0 \cdot 44 \\
(1.5: 1)\end{array}$ & $\begin{array}{l}+0.34 \\
(1.4: 1)\end{array}$ & $\begin{array}{l}+1 \cdot 13 \\
(3 \cdot 1: 1)\end{array}$ & $\begin{array}{l}+0.19 \\
(1.4: 1)\end{array}$ & $\begin{array}{l}-0 \cdot 18 \\
(0 \cdot 7: 1)\end{array}$ \\
\hline $\begin{array}{l}\text { Neighbour effect as } \\
\text { percentage of direct effect }\end{array}$ & $+20.1 \%$ & $+27.4 \%$ & $+20.0 \%$ & $+31.9 \%$ & $(-) \S$ \\
\hline $\begin{array}{l}\text { Mean value of RMS } \\
\text { (blocks)/RMS (neighbours) } \ddagger\end{array}$ & $1 \cdot 12$ & 0.88 & $1 \cdot 16$ & 0.90 & 0.98 \\
\hline
\end{tabular}

* Figures in parentheses indicate numbers of derived variates representing the means of the separate assessments on the two sides of the plots.

† Effects are calculated from the transformed data and represent the difference between inoculation with rhynchosporiuminfected straw and spraying twice with prochloraz, in February and March.

$\ddagger$ Residual mean squares (RMS) derived from analyses assuming a blocks structure (16 blocks of 5 plots), in which effects of neighbouring treatments are ignored, and analyses which recognise the imposed balance, and hence effects of neighbouring treatments, but take no account of blocks.

$\S$ No value has been entered here because the denominator is very small and the estimate consequently unreliable.

and March (the first six periods of exposure) southwestern neighbours apparently had very large effects $(42.4 \%)$ while effects of north-eastern neighbours were negligible $(-2 \cdot 8 \%)$. Subsequently, however, the average effects of south-western and north-eastern neighbours were very similar $(20.8$ and $22.8 \%$, respectively).

The average effect of these neighbouring treatments on numbers of spores washed from sampled plants (based on seven sampling dates) was, similarly, $20.0 \%$ of the direct effect. Again, south-western neighbours were apparently more important than north-eastern neighbours $(30.1$ and $8.5 \%$, respectively) but in these data there was no evidence of a consistent change with time.

Lesions on the seedlings taken to measure numbers of spores were counted on only three dates (in December, January and February). Over this period the mean neighbour effect was $27.4 \%$ of the direct effect but these data, in contrast to most others, suggested that it was north-eastern neighbours that had most effect $(42.0 v .12 .8 \%)$. However, this effect of north-eastern neighbours mostly derives from very large and significant effects seen only in the February data, previously described above.

The six variates measuring severity of leaf blotch are all derived from samples taken on one date in June and are, therefore, very highly correlated. They showed a mean neighbour effect that was $31.9 \%$ of the direct effect and, again, it was south-western neighbours that were most important (47.1 v. 16.8\%). In common with most other variates, the disease data showed that plots interacted most with the adjacent sides of their immediate neighbours, as would be expected. However, the disease data also suggested that the north-eastern sides of plots were less affected by the immediately adjacent north-eastern neighbours than they were by the more distant south-western neighbours $(12 \cdot 2$ and $23.2 \%$, respectively).

On average, the treatments we have chosen to compare had no direct effect on powdery mildew (Table 6). This is because the significant negative effects on amounts of mildew on second youngest leaves that we have described above (indicating more mildew in the twice-sprayed plots than in the inoculated) were obscured by differences in amounts of mildew on the flag leaves that were, however, not significant. In contrast, negative effects of these treatments applied to neighbouring plots to the south-west, were evident in the data for both leaves.

The increases in precision achieved by using the neighbour analyses in preference to the blocks analyses were mostly very much smaller (Table 6) than in the comparable experiment in 1981, despite the fact that there were clearly substantial inter-plot 


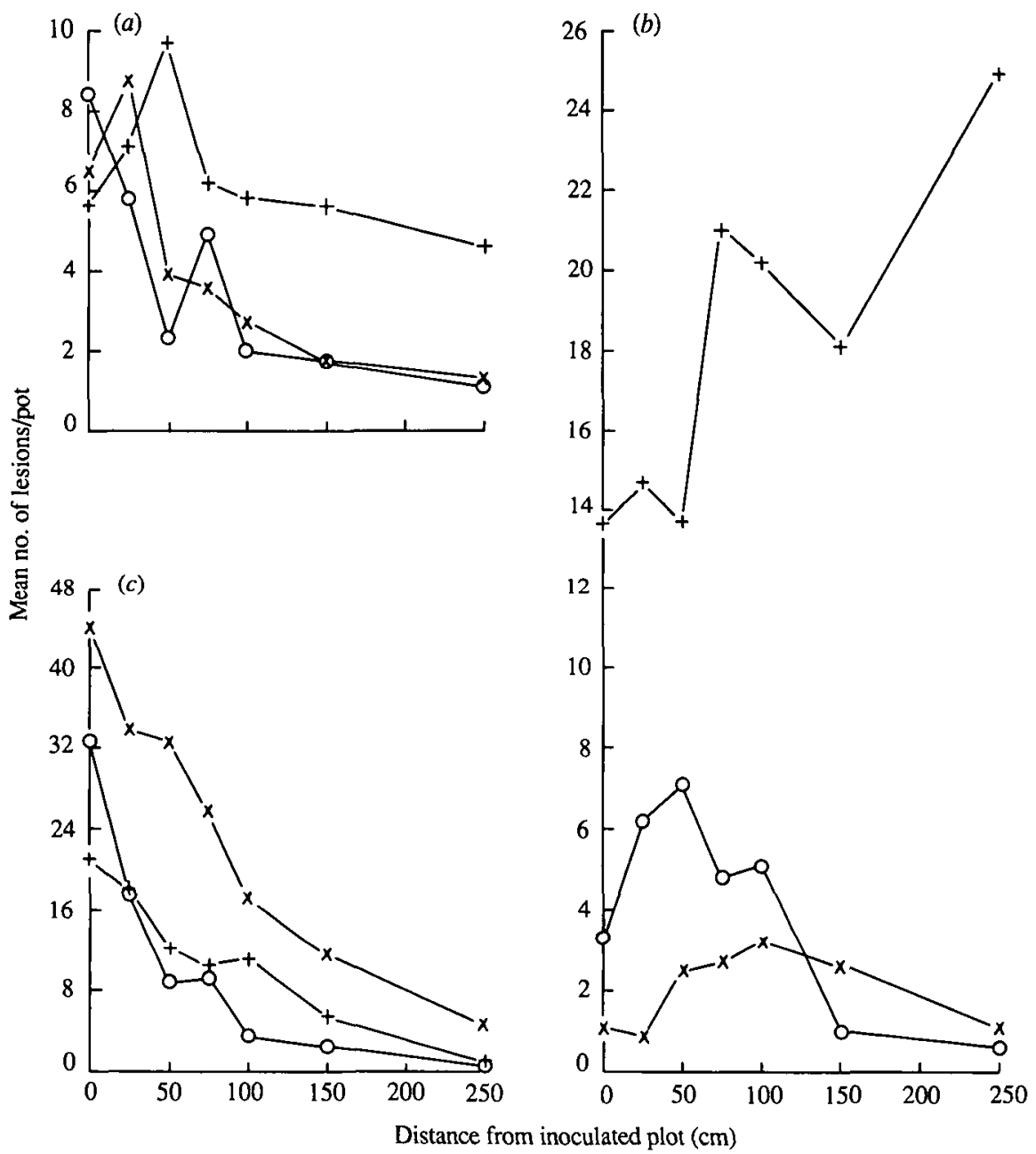

Fig. 3. Gradients of leaf blotch detected on seedlings of Maris Otter winter barley exposed near to inoculated plots of Maris Otter in surrounding crops of winter barley, namely, Athene in 1980-l (a); Maris Otter in 1980-1 (b); Igri in 1981-2 (c). Each gradient in 1980-1 is based on the geometric means of results for two successive periods between 11 December and 19 January $(0-0), 2$ February-12 March $(x-x)$ or 12 March-2 April $(+-+)$. Each gradient in 1981-2 is based on the geometric means of results for three successive periods between 3 December and 27 January $(O-O)$, 9 February-4 March $(x-x)$ or 4 March-18 March $(+-+)$.

interactions in both experiments. This contrast between the 2 years suggests that there was much greater heterogeneity in 1982 than in 1981 and that blocks were at least partially effective in removing this. Nevertheless, overall differences between blocks were seldom significant in the analyses of variance and there was no evidence that justified any form of positional analysis of the disease data.

\section{Effects of neighbouring treatments on growth and yield}

The yield data provided evidence of a fertility profile which was fitted by two independent Fourier series (each using two cosine and two sine terms), one for each row of plots. The variance accounted for by these covariates was highly significant $(P<0.001)$. Thousand-grain weights also showed evidence of a fertility profile, which was broadly similar to that exhibited by grain yields and also highly significant. However, there was no evidence that treatments to neighbouring plots affected either grain yields or 1000-grain weights.

\section{Infection gradients (1980-1 and 1981-2)}

Infection gradients, measured on seedlings exposed in 'resistant' barley (cvs Athene and Igri, respectively, in 1980-1 and 1981-2) downwind of Maris Otter source plots, were very steep in all tests done between 
December and early March with most infections occurring within $1 \mathrm{~m}$ of the source (Fig. $3 a$ and $c$ ). Gradients during November 1981 were similarly very steep but numbers of infections were then small so these data have been omitted from Fig. $3 c$. In March-April 1981, gradients were less pronounced than before, probably reflecting the fact that leaf blotch was by then common on cv. Athene; maximum numbers of infections then occurred $50 \mathrm{~cm}$ from the downwind edge of the source plot. In contrast, clear infection gradients were detected in March 1982 although they were rather less steep than they had been in the preceding months.

Seedlings exposed in cv. Maris Otter surrounding a Maris Otter source plot in December 1980 and January 1981, also detected clear gradients but maximum numbers of infections occurred $50 \mathrm{~cm}$ from the downwind edge of the source (Fig. $3 b$ ). In February and March 1981, numbers of infections on seedlings exposed in the Maris Otter surround were, inexplicably, smaller than on seedlings exposed in the Athene surround on the same dates (Fig. $3 a$ and $b$ ) and numbers increased up to a distance of $1 \mathrm{~m}$ from the source. By late March 1981, the disease was well established in the Maris Otter surround and numbers of infections on the exposed seedlings were then much larger than on those seedlings exposed in the Athene surround. Numbers of infections generally increased with distance from the source plot, to a maximum at $2.5 \mathrm{~m}$, the furthest distance tested.

\section{DISCUSSION}

Previous experiments to examine the importance of inter-plot interference in experiments with cereal pathogens have mostly focused on fungal species with easily dispersed, air-borne spores such as the mildews or rusts (e.g. Jenkyn \& Bainbridge, 1974; Bainbridge \& Jenkyn, 1976; Jenkyn et al. 1979; Bowen et al. 1984; Parlevliet \& van Ommeren, 1984). The results described in this paper show that similar interactions can occur in experiments with a pathogen ( $R$. secalis) that is principally, if not entirely, dispersed by rainsplash. Such interactions occurred despite the fact that a large proportion of splash-dispersed spores is usually deposited very close to the source (Fitt \& McCartney, 1986). Movement between plots is, therefore, likely to be small compared with that which occurs with airborne pathogens. However, in experiments with autumn-sown cereals, such as most of those described in this paper, spores may be dispersed on numerous occasions in the autumn and winter, during which time crops are mostly in the seedling stages and are relatively inefficient at filtering spores from the air. Our results suggest that even though individual dispersal events probably transfer few spores between plots, the cumulative effects, reinforced by secondary spread within the recipient plots, can be large enough for this to be a potentially important factor influencing the validity and precision of experiments with these pathogens.

The interactions that we detected were, perhaps predictably, complex but, with only rare exceptions, made biological sense. The greater the difference in amounts of disease between adjacent plots, for example, the larger was the interaction between them. Thus amounts of $R$. secalis in unsprayed or oncesprayed plots were typically larger where neighbouring plots were inoculated than where neighbouring plots on the same side were twice sprayed. Interactions also tended to be less evident during the early months, when there was relatively little disease in any plot, and again at the end of the season, when most plots were severely diseased. Neighbouring plots to the west or south-west generally had larger effects than did those to the east or north-east, probably reflecting, in part, the frequency of winds from that direction. Of probably equal importance, however, is that in the U.K., westerly and south-westerly winds are typically warm, humid and often associated with rain and, therefore, favour spore dispersal and infection. Given the complexity of these interactions, the calculated mean effects of contrasting treatments on neighbouring plots (averaged over groups of related variates, e.g. Tables 2 and 6), which were commonly $20-30 \%$ of the direct effects of the same treatments on the appropriate transform scales, are unlikely to be exaggerated and certainly underestimate the largest effects that can occur.

The greater severity of leaf blotch (whether measured as symptoms on leaves or numbers of spores on sampled plants) in untreated and once-sprayed plots adjacent to inoculated than in similarly treated plots adjacent to twice-sprayed, can probably mostly be explained by the movement of inoculum into them from the inoculated plots, i.e. positive interference (James et al. 1973). Negative interference, in which there is a net loss of inoculum from plots adjacent to others with less disease, leading to less disease than 'expected' in the former, has also been detected in experiments with potato blight (James et al. 1973, 1976) and barley powdery mildew (Jenkyn et al. 1979) and may have contributed to the results that we describe. However, our experiments were not well suited to distinguish between positive and negative interference because all plots had differently treated neighbours and the contrasts we were able to make mostly represented the combined effects of the two types of interference. Nevertheless, the inoculated plots could have been subjected only to negative interference and Fig. l $a$, for example, shows a consistent effect of differently treated neighbours on inoculated plots after the first sprays were applied. Generally, such effects on inoculated plots were small, as might perhaps be expected if the inoculum moving 
out of a plot represents only a small proportion of total production. Even differences among the inoculated plots, however, are likely to underestimate the potential effects of negative interference on them because all of them usually had more disease than their neighbours and all were, therefore, subject to that risk to at least some extent. To detect negative interference in the inoculated plots we should, ideally, have compared inoculated plots that had neighbours that were either inoculated or repeatedly sprayed. We come closest to these conditions in Expt 4 where we included plots that were uninoculated and unsprayed, in which the disease was as severe as in the inoculated from about mid-April. However, negative interference is likely to be especially important during the early stages of an epidemic, when inoculum concentrations are limiting, and at that time, and until the first sprays were applied, all neighbours of the inoculated plots were identically treated.

Some further evidence for the potential importance of negative interference in experiments with splashdispersed pathogens is provided by the infection gradients measured in untreated Maris Otter. Thus in March-April 1981, numbers of infections on exposed seedlings increased steeply to a distance of $2.5 \mathrm{~m}$ (the maximum tested) from the downwind edge of the source. These numbers presumably reflect the patterns of spore dispersal during the period of exposure, superimposed on the pattern of distribution of the disease within the crop, itself reflecting previous dispersal events. The results suggest that there was erosion of inoculum from the upwind edge of the trap crop, despite the presence of a potent source of inoculum adjacent to that edge, that was sufficient to limit disease development for a distance of at least $2.5 \mathrm{~m}$.

The treatments that were applied generally had the desired effects and leaf blotch was usually more severe in the inoculated plots than in the sprayed (for details see Jenkyn et al. 1989). Effects of neighbouring treatments usually reflected these differences. However, this appeared not to be so in May 1981 (Expt 2) when symptoms on the leaves were often less severe where neighbouring plots were inoculated than where they were twice sprayed. We can offer no explanation for this particular result although similar effects in the mildew data can be explained (see below).

Effects on other diseases were more complex. Thus mildew and brown rust were typically less severe in the straw-inoculated plots than in the uninoculated, presumably because severe leaf blotch in the former lessened the area of leaf tissue available for infection by these other diseases. The fungicide sprays decreased mildew but the compounds used were not chosen for this purpose and their effects on this disease were generally short-lived. Thus the relative potency of different plots, as sources of mildew inoculum, changed considerably with time. Before fungicide sprays were applied, and after their effects had worn off, the uninoculated plots generally had much more mildew than the inoculated but the difference was much reduced or reversed in the period immediately after spraying. As a consequence, effects of neighbouring treatments also changed with time. Furthermore, there were occasions when the direct and neighbour effects operated in opposite directions. At first sight, such apparently contradictory observations seem difficult to reconcile. However, differences between plots resulting from the direct effects of treatments must usually precede the development of effects in neighbouring plots. Thus the application of a fungicide presumably affected mildew development in the sprayed plots almost immediately but, assuming no significant drift of spray or vapour, would not have been expected to affect latent infections in their neighbours so there was a delay before corresponding differences in disease in these plots were apparent. Subsequently the control of mildew in the sprayed plots was reflected in the amounts of disease in their neighbours and we could, therefore, expect to detect direct and neighbour effects that operated in the same direction. Even later, mildew often became relatively more severe in the sprayed plots than in the unsprayed but a delay before this was reflected in amounts of mildew in the neighbouring plots could again be expected, so they continued to reflect the earlier differences and the direct and neighbour effects operated in opposite directions.

Among the mildew data, the result most difficult to explain is that obtained in June 1982 (Expt 4). On that occasion, mildew in the uninoculated, unsprayed plots was most severe where the south-western neighbour had been sprayed in February or February and March and least severe where the south-western neighbour had been inoculated, reflecting the direct effects of these treatments in the plots to which they were applied, measured on the same date. The sprayed plots showed broadly similar effects. In contrast, the inoculated plots had least mildew where the southwestern neighbour had been sprayed in February or February and March and most where the southwestern neighbour was untreated or sprayed only in March. Such a pattern might have been expected soon after the February spray was applied although the disease was not assessed at that time. Thus if the results are to be believed, they imply that in the inoculated plots early-established differences persisted while in the uninoculated, unsprayed plots they were obscured by later interactions.

Several different methods were used to measure $R$. secalis in these experiments and some comments on their usefulness seem appropriate. Exposed seedlings measured the relative amounts of effective inoculum (i.e. that which was able to infect) that was deposited on them during the period of exposure, whether this came from the plots in which they were exposed or 
from neighbouring plots. It was relatively simple and quick to place the pots of seedlings in the plots and to remove them at the end of the exposure period but considerable effort was needed to prepare the large numbers of pots required and losses in the field due to frost damage were sometimes a problem. Usually, numbers of infections on these seedlings were significantly affected by treatments to plots but much less often by treatments to neighbouring plots.

Numbers of spores washed from crop samples indicated relative amounts of disease on the sampled plants, including that on leaves which had since died but still supported sporulation, and their relative potency as inoculum sources. They reflected the cumulative effects of treatments to plots and to neighbouring plots prior to the time when samples were taken. Sampling was tedious and time-consuming, especially during the winter, and processing the samples (i.e. removing the roots, washing the leaf and stem tissue and counting the spores) also took much time and effort. The data obtained are not strictly comparable with those obtained from exposed seedlings because crop samples were usually taken from the edges of plots (but never from the outermost rows) whereas seedlings were always exposed in the centres of plots. In part, crop samples were taken from the edges of plots to avoid damage to the areas in which yields were measured but also to allow us to make comparisons between the opposite sides of the plots. Spore counts were also based on a minimum of 20 plants per plot, compared with only 5 or 6 seedlings, each with only 2-3 leaves, that were usually used in the exposed seedlings tests, so the effective sample sizes were very different. It is perhaps not surprising, therefore, that the spore counts were generally more informative than the exposed seedling tests, and more frequently detected effects of treatments to neighbouring plots.

Symptoms of leaf blotch were measured by counting lesions on the plants sampled to estimate numbers of spores. However, the data tended to be relatively variable, probably reflecting the difficulties experienced in identifying some of the symptoms, especially on the lower, senescing leaves. Other samples, mostly taken at later growth stages, were used to estimate areas affected on the youngest 2-3 leaves. These data also tended to be variable but they nevertheless often revealed significant effects of treatments to neighbouring plots. Such effects seemed especially marked in samples taken from the February-sown plots in Expt 3, probably reflecting the extreme contrast between them and the autumn-sown, inoculated plots which were potent, and almost certainly the most important, sources of inoculum for infecting the February-sown plots from the time the latter emerged in March. Under these circumstances, the relatively short period during which the February-sown plots remained in the seedling stages may have favoured the detection of inter-plot interactions because it probably limited secondary spread within and between plots so that early differences persisted.

Samples taken to estimate areas on the leaves affected by leaf blotch were, like those used to estimate numbers of spores, taken from the edges of plots and may, therefore, have favoured the detection of inter-plot interactions. Nevertheless, the effects were often large enough to be detected in analyses of data representing the average values for the two sides of each plot. Furthermore, in June 1982 (Expt 4) amounts of leaf blotch on the north-eastern sides of plots were apparently less affected by their immediately adjacent north-eastern neighbours than they were by the more distant south-western neighbours, suggesting that the interactions that we describe were often sufficiently large to have effects that extended well beyond the discard areas in which the measurements were made and into the areas in which yields were measured.

Despite the often large effects of neighbouring treatments on leaf blotch there were no effects of neighbouring treatments on grain yield. However, this is not surprising because the direct effects of treatments on grain yield were mostly small and only poorly related to the observed effects of the treatments on leaf blotch and seedling growth (Jenkyn et al. 1989).

The results that are presented in this and previous papers provide convincing evidence that inter-plot interference is a widespread and potentially important phenomenon in many experiments. The balanced designs (Dyke \& Shelley, 1976) that we used were chosen to enable us to detect and measure such interactions, and proved successful in doing so, but it is important to emphasize the problems that can arise in the analysis of such experiments, and the care that is necessary in their interpretation. Standard analyses of variance, applied to individual variates, provide the simplest test for the occurrence of interactions between neighbouring treatments and give a useful indication of their relative magnitude. However, treatments will usually have much smaller effects on neighbouring plots than they do on the plots to which they are applied. Such interactions may, therefore, be difficult to detect against the background variation using accepted criteria but it does not follow that they are necessarily unimportant and can be ignored. Thus, relatively small but consistent effects may provide more convincing evidence of inter-plot interactions than occasional, much larger, effects which, although significant, may fluctuate in direction and not make good biological sense. However, even consistent effects must be treated with caution because in any one experiment, successive samples are taken from the same plots and results are, therefore, highly correlated. The risks of spurious consistency are even greater where the same samples are used to derive more than 
one variate (e.g. areas affected by diseases on different leaves).

Similar cautions apply to our estimates of the relative effects of treatments on neighbouring plots compared with their effects on the plots to which they were applied. By averaging over groups of related variates, we decreased the risks that the estimates were biased by extraneous variation but not by correlated, but spurious, differences. Clearly, consistency of results between different experiments provides more convincing evidence for these effects than consistency within any one experiment.

The experiments described here were mostly quite large but it is reasonable to expect that biologically significant interactions will often occur principally in only one treatment, representing very few plots, also increasing the risk of reaching erroneous conclusions. Fungicide-treated plots, for example, will become susceptible to reinfection as the effects of the treatment wear off and may then be especially sensitive to the effects of neighbouring treatments. If there is also a strong directional component, perhaps as a result of winds that are consistently from one direction, then in a single replicate of one of our four-treatment, balanced designs, a meaningful interaction may depend on only six plots. If, by chance, the plots representing one such contrast are arranged as two groups of three, and these groups are widely separated from one another, then the chances of detecting spurious effects are clearly substantial. The risk is illustrated by the lodging and yield data in Expt 2 . These suggested that there were significant effects of neighbouring treatments but, after close examination, the effects were attributed to patchy distribution of lodging in the experiment and, therefore, dismissed as spurious.

Franklin (1981) also recognized this type of weakness and, for the balanced designs that he generated, he calculated two parameters, $S_{2}$ and $S_{3}$, being the sum of squares and sum of cubes, respectively, of the mean distances of the plots of each treatment from the centre of the design (in one-plot units). These parameters summarize the irregularity of the distribution of the treatments across the site. For our purposes, however, it is the distribution of treatment combinations on pairs of adjacent plots, rather than the single treatments themselves, that is of paramount importance. Thus, if the treatment symbols are A, B, $C, \ldots$, then one such contrast is $A$ with left-hand neighbour B, v. A with left-hand neighbour $\mathrm{C}$. Retrospectively, we examined the distribution of such contrasts in the four-treatment design of Expt 2 and the five-treatment design of Expt 4. In the former, with 24 contrasts of interest, there were five that were based on non-overlapping sets of plots, i.e. where all plots of one set were to the left of all plots of the other. In Expt 4, none of the 60 relevant contrasts was based on non-overlapping sets, although two were based on sets with very little overlap. The layout of this experiment in two rows of plots introduced further complications because several contrasts were largely (though not entirely) confounded with rows. We are confident, however, that this did not contribute to any of the significant interactions that we describe. It would be possible to select from among available designs to minimize the number of contrasts based on undesirable patterns but we would be reluctant to take this further step away from true randomization without careful consideration.

Although we attach importance to the consistency of effects, there may be good biological reasons for occasional inconsistency, as shown by the mildew data. Similarly, occasional evidence for effects of north-eastern neighbours in Expt 4 is not necessarily incompatible with the observed dominance of southwestern neighbours. In late December 1981, for example, there was a period of light rain when the winds were from the east and north-east (that might have allowed spore dispersal) followed by 7 days of very mild weather (that might have allowed infection) and this could explain the effects of north-eastern neighbours on numbers of infections on plants sampled in early February. Subsequent effects on numbers of spores might have been expected but could easily have been obscured by the much greater accumulated effects of south-western neighbours.

Soil heterogeneity is a potential problem in any field experiment and especially those with many plots and little replication. In our balanced designs, the problems are further compounded by the need to arrange them in long lines. However, in the designs we used, the allocation of treatments to plots was constrained so that they were also arranged in blocks. We could, therefore, analyse the data assuming a blocks $\times$ treatments structure (but ignoring the effects of neighbouring treatments). Examining for differences between blocks provided a convenient screen for any positional effects that might need to be recognized when analysing the results to examine effects of neighbouring treatments. On this basis, there was little evidence to suggest that positional variation significantly affected the disease data, perhaps reflecting, in part, their inherent random variability. In contrast, grain yields and 1000-grain weights were affected by such variation in all the experiments. To allow for this variation, in analyses to examine the effects of neighbouring treatments on these variates we made covariance adjustments using four-term Fourier series. Recently there has been much interest in using nearest-neighbour (NN) models of various types to decrease the effects of positional variation but we chose not to use them because we were unable to make an objective choice between the many alternative methods which have been suggested. The problem can be illustrated by reference to the yields from a barley mildew experi- 
ment at Rothamsted in 1975 that also showed marked positional variation. In addition to the two analyses offered in the original publication (Jenkyn et al. 1979), a further two were described by Draper \& Guttman (1980). We have also found several references to $\mathrm{NN}$ analyses of the same data including Wilkinson et al. (1983; one analysis, with other possible methods indicated by Green et al., Mead and Nelder in the discussion of this paper), Martin (1984; four analyses), Schwarzbach (1984; one analysis), Green, Jennison \& Seheult (1985; nine analyses) and Gleeson \& Cullis (1987; three analyses). Although many of the estimated treatment effects offered by these authors are equal, or very nearly so, there are some larger discrepancies and not all follow the same pattern. Most of the NN analyses do not assess effects of interference. Our fears (Jenkyn et al. 1979, and Dyke in discussion of Wilkinson et al. 1983) that NN analyses may sometimes mask real treatment-interference effects, have not been allayed by any of these publications and we have extended our series of simulations with results which we hope will be reported soon. Meanwhile, therefore, we have chosen to use only the relatively simple adjustments for positional variation used by Jenkyn et al. (1979). Since the 1975 barley yields have proved attractive to analysts we present in Appendix Table 1 the yields of Expt 4 (with five treatments) which showed marked positional variation (but no real effects of neighbouring treatments), so that other forms of analysis can be applied to them.
An important consequence of inter-plot interactions in randomized experiments is that they increase residual variation. Although the 'blocks' and 'neighbour' analyses that we used are not strictly comparable, they do illustrate the potential significance of such effects. Thus in 1981 (Expt 2), average residual mean squares were up to $60 \%$ greater where disease data were analysed using the blocks analysis than where they were analysed recognizing the effects of neighbouring treatments. In 1982 (Expt 4) average effects of treatments on neighbouring plots were comparable to those detected in Expt 2 but mean decreases in residual mean squares as a result of using neighbour analyses instead of blocks analyses were much smaller. This probably indicates relatively more positional variation in the disease data in the latter year which was, at least partially, accounted for by blocks. It was, nevertheless, too small to be significant and to justify recognition in the neighbour analyses of these data. Taken together, however, the results illustrate the potential for inter-plot interference to affect the validity and precision of field experiments with splash-dispersed pathogens as well as those with the air-borne pathogens with which these risks are usually associated.

We thank the Rothamsted farm and small-plots staff for their painstaking help with the field work and Mrs T. L. Feekins and Mrs N. F. Creighton for technical assistance.

\section{REFERENCES}

ANON. (1976). Manual of plant growth stage and disease assessment keys. London: Ministry of Agriculture, Fisheries and Food, Agricultural Development and Advisory Service.

Bainbridge, A. \& Jenkyn, J. F. (1976). Mildew reinfection in adjacent and separated plots of sprayed barley. Annals of Applied Biology 82, 477-484.

Bowen, K. L., Teng, P. S. \& Roelfs, A. P. (1984). Negative interplot interference in field experiments with leaf rust of wheat. Phytopathology 74, 1157-1161.

DraPER, N. R. \& GUTTMAN, I. (1980). Incorporating overlap effects from neighbouring units into response surface models. Applied Statistics 29, 128-134.

Dyke, G. V. \& Shelley, C. F. (1976). Serial designs balanced for effects of neighbours on both sides. Journal of Agricultural Science, Cambridge 87, 303-305.

FitT, B. D. L. \& McCartney, H. A. (1986). Spore dispersal in splash droplets. In Water, Fungi and Plants (ed. P. G. Ayres \& L. Boddy). Cambridge: Cambridge University Press.

Franklin, M. F. (1981). Computer construction of experimental plans. Ph.D. Thesis, University of Edinburgh.

Gleeson, A. C. \& Cullis, B. R. (1987). Residual maximum likelihood (REML) estimation of a neighbour model for field experiments. Biometrics 43, 277-288.

Green, P., Jennison, C. \& Seheult, A. (1985). Analysis of field experiments by least squares smoothing. Journal of the Royal Statistical Society B 47, 299-315.

James, W. C., Shih, C. S., Callbeck, L. C. \& Hodgson, W. A. (1973). Interplot interference in field experiments with late blight of potato (Phytophthora infestans). Phytopathology 63, 1269-1275.

James, W. C., Shih, C. S., Hodgson, W. A. \& Callbeck, L. C. (1976). Representational errors due to interplot interference in field experiments with late blight of potato. Phytopathology 66, 695-700.

Jenkyn, J. F. \& Baindridge, A. (1974). Disease gradients and small plot experiments on barley mildew. Annals of Applied Biology 76, 269-279.

Jenkyn, J. F., Bainbridge, A., Dyke, G. V. \& Todd, A. D. (1979). An investigation into inter-plot interactions, in experiments with mildew on barley, using balanced designs. Annals of Applied Biology 92, 11-28.

JENKYN, J. F., DYKE, G. V. \& TODD, A. D. (1983). Effects of fungicide movement between plots in field experiments. Plant Pathology 32, 311-324.

Jenkyn, J. F., Stedman, O. J., Dyke, G. V. \& Todd, A. D. (1989). Effects of straw inoculum and fungicides on leaf blotch (Rhynchosporium secalis), growth and yield of winter barley. Journal of Agricultural Science, Cambridge, 112, 85-95.

Martin, R. J. (1984). Some theoretical results on the design 
and analysis of experiments with second-order stationary spatially correlated errors and some fits for such error processes. In Spatial Methods in Field Experiments (Biometric Society Workshop at the University of Durham, 13 December 1984).

Parlevliet, J. E. \& van Ommeren, A. (1984). Interplot interference and the assessment of barley cultivars for partial resistance to leaf rust, Puccinia hordei. Euphytica 33, 685-697.

SCHWARZBACH, E. (1984). A new approach in the evaluation of field trials. The determination of the most likely genetic ranking of varieties. Vorträge für Pflanzenzüchtung 6 , 249-259

van der Plank, J. E. (1963). Plant Diseases: Epidemics and Control. London: Academic Press.

Wilkinson, G. N., Eckert, S. R., Hancock, T. W. \& MAYO, O. (1983). Nearest neighbour (NN) analysis of field experiments. Journal of the Royal Statistical Society $B$ 45, 151-211.

Wilkinson, G. N. \& Rogers, C. E. (1973). Symbolic description of factorial models for analysis of variance. Applied Statistics 22, 392-399.

Appendix Table 1. Treatments and grain yields of individual plots in Expt $4^{*}$

\begin{tabular}{|c|c|c|c|c|c|}
\hline $\begin{array}{l}\text { Plot } \\
\text { no. }\end{array}$ & Treatment & $\begin{array}{c}\text { Grain } \\
\text { yield } \\
(\mathrm{t} / \mathrm{ha})\end{array}$ & $\begin{array}{c}\text { Plot } \\
\text { no. }\end{array}$ & Treatment & $\begin{array}{c}\text { Grain } \\
\text { yield } \\
\text { (t/ha) }\end{array}$ \\
\hline (01) & S1 & 5.58 & 30 & NONE & 5.99 \\
\hline 02 & INOC & 4.90 & 31 & $\mathrm{~S} 2$ & 5.96 \\
\hline 03 & SI & $5 \cdot 30$ & 32 & INOC & $5 \cdot 15$ \\
\hline 04 & $\mathrm{~S} 2$ & 5.99 & 33 & NONE & 5.85 \\
\hline 05 & NONE & $5 \cdot 44$ & 34 & SI & $6 \cdot 17$ \\
\hline 06 & $\mathrm{~S} 1+\mathrm{S} 2$ & $6 \cdot 28$ & 35 & $\mathrm{~S} 2$ & 5.69 \\
\hline 07 & NONE & 5.82 & 36 & $\mathrm{~S} 1+\mathrm{S} 2$ & 5.83 \\
\hline 08 & $\mathrm{~S} 1+\mathrm{S} 2$ & 5.96 & 37 & INOC & 4.83 \\
\hline 09 & SI & $5 \cdot 31$ & 38 & $\mathrm{~S} 2$ & 5.07 \\
\hline 10 & INOC & 4.03 & 39 & NONE & $5 \cdot 18$ \\
\hline 11 & $\mathrm{~S} 2$ & $4 \cdot 61$ & 40 & S1 & 5.09 \\
\hline 12 & INOC & $4 \cdot 29$ & 41 & $\mathrm{~S} 1+\mathrm{S} 2$ & 5.24 \\
\hline 13 & $\$ 2$ & $4 \cdot 34$ & (42) & SI & 5.39 \\
\hline 14 & SI & $4 \cdot 46$ & (43) & $\mathrm{S} 1+\mathrm{S} 2$ & $4 \cdot 78$ \\
\hline 15 & NONE & $4 \cdot 66$ & 44 & S1 & $4 \cdot 70$ \\
\hline 16 & $\mathrm{SI}+\mathrm{S} 2$ & $5 \cdot 14$ & 45 & $S 1+S 2$ & $5 \cdot 04$ \\
\hline 17 & INOC & 4.68 & 46 & $\mathrm{~S} 2$ & 4.97 \\
\hline 18 & $\mathrm{~S} 1+\mathrm{S} 2$ & $5 \cdot 40$ & 47 & NONE & 4.96 \\
\hline 19 & SI & 4.96 & 48 & INOC & $4 \cdot 39$ \\
\hline 20 & NONE & 5.01 & 49 & S1 & 4.91 \\
\hline 21 & S2 & 5.04 & 50 & INOC & $4 \cdot 54$ \\
\hline 22 & NONE & 5.21 & 51 & NONE & $5 \cdot 07$ \\
\hline 23 & $\mathrm{~S} 2$ & $5 \cdot 29$ & 52 & $\mathrm{~S} 1+\mathrm{S} 2$ & $5 \cdot 20$ \\
\hline 24 & SI & $5 \cdot 55$ & 53 & $\mathrm{~S} 2$ & $5 \cdot 14$ \\
\hline 25 & INOC & $5 \cdot 33$ & 54 & $\mathrm{~S} 1+\mathrm{S} 2$ & $4 \cdot 97$ \\
\hline 26 & $\mathrm{~S} 1+\mathrm{S} 2$ & $5 \cdot 82$ & 55 & S2 & $5 \cdot 07$ \\
\hline 27 & INOC & $5 \cdot 03$ & 56 & INOC & $4 \cdot 70$ \\
\hline 28 & S1 & $5 \cdot 75$ & 57 & Sl & $5 \cdot 11$ \\
\hline 29 & $\mathrm{~S} 1+\mathrm{S} 2$ & 5.85 & 58 & NONE & $5 \cdot 36$ \\
\hline
\end{tabular}

\begin{tabular}{|c|c|c|c|c|c|}
\hline $\begin{array}{l}\text { Plot } \\
\text { no. }\end{array}$ & Treatment $\ddagger$ & $\begin{array}{c}\text { Grain } \\
\text { yield } \\
\text { (t/ha) }\end{array}$ & $\begin{array}{c}\text { Plot } \\
\text { no. }\end{array}$ & Treatment & $\begin{array}{c}\text { Grain } \\
\text { Yield } \\
\text { (t/ha) }\end{array}$ \\
\hline 59 & S1 & 5.43 & 73 & $\mathbf{S 2}$ & 5.49 \\
\hline 60 & NONE & $5 \cdot 39$ & 74 & $\mathrm{~S} 1+\mathrm{S} 2$ & $5-28$ \\
\hline 61 & INOC & $4 \cdot 89$ & 75 & S1 & $5 \cdot 17$ \\
\hline 62 & $\mathrm{~S} 1+\mathrm{S} 2$ & $5 \cdot 18$ & 76 & $\mathrm{~S} 2$ & $5 \cdot 10$ \\
\hline 63 & S2 & $5 \cdot 30$ & 77 & S1 & $5 \cdot 13$ \\
\hline 64 & SI & 5.43 & 78 & $\mathrm{~S} 1+\mathrm{S} 2$ & $4 \cdot 67$ \\
\hline 65 & $\mathrm{~S} 2$ & $5 \cdot 50$ & 79 & INOC & 4.63 \\
\hline 66 & INOC & $4 \cdot 82$ & 80 & NONE & 5.03 \\
\hline 67 & $\mathrm{~S} 1+\mathrm{S} 2$ & $5 \cdot 67$ & 81 & INOC & $4 \cdot 60$ \\
\hline 68 & NONE & 5.87 & 82 & $\mathrm{~S} 2$ & $5 \cdot 36$ \\
\hline (69) & INOC & $6 \cdot 12$ & 83 & $\mathrm{~S} 1+\mathrm{S} 2$ & $4 \cdot 78$ \\
\hline (70) & NONE & $6 \cdot 03$ & 84 & NONE & $5 \cdot 10$ \\
\hline 71 & INOC & $5 \cdot 34$ & 85 & S1 & $5 \cdot 70$ \\
\hline 72 & NONE & 6.63 & $(86)$ & INOC & $5 \cdot 48$ \\
\hline
\end{tabular}

* Plots 01 to 42 were arranged in a single line running approximately north-east (plot 01) to south-west (plot 42). The remaining plots were arranged in a second line to the north-west of, and parallel to, the first. The two lines were slightly offset and a break was necessary between plots 69 and 70 to avoid a dell. Plots 43,69 and 70 were opposite plots 04,30 and 34 , respectively. The numbers of 'dummy' plots, the yields of which were excluded from the analyses described in this paper, are shown in parentheses.

$\dagger$ NONE, no fungicide or inoculation treatment; S1, prochloraz spray on I February; S2, prochloraz spray on 22 March; S1 + S2, prochloraz sprays on 1 February and 22 March; INOC, inoculated with infected straw. 